\title{
Technological innovation in the winery addressing oenology 4.0: Testing of an automated system for the alcoholic fermentation management
}

\author{
Valentina Giovenzana, ${ }^{1}$ Stefano Baroffio, ${ }^{1}$ Roberto Beghi, ${ }^{1}$ Andrea Casson, ${ }^{1}$ Alessia Pampuri, ${ }^{1}$ \\ Alessio Tugnolo, ${ }^{1}$ Diego De Filippi, ${ }^{2}$ Riccardo Guidetti ${ }^{1}$ \\ ${ }^{1}$ Department of Agricultural and Environmental Sciences - Production, Landscape, Agroenergy, Università degli Studi \\ di Milano, Milano; ${ }^{2}$ HTS Enologia - Contrada Amabilina, Marsala (TP), Italy
}

\begin{abstract}
In recent years, the use of automated machine tools in the wine industry has increasingly gained ground to simplify and optimize winemaking, complying with Industry 4.0 requirements. This work aimed to analyse a system for the automatic management of yeast nutrition in alcoholic fermentation in terms of environmental, management, and economic performance in comparison with traditional fermentation management. The automated system is a transportable and easily installable place and start system, equipped with a control unit and rods for the dosage of nutrients, and it works with a memory unit in which fermentative kinetics curves are loaded. The curves are predefined or customized according to oenologists' needs. Hence, fermentation time, manpower, nutrients, oxygen, water, and energy consumption were evaluated concerning the alcoholic fermentation process. The analysis was carried out considering two different Italian wineries with different working capacities. Furthermore, life cycle assessment methodology and variable costs analysis was performed. Overall, the automated system reveals to be a promising investment, especially if applied to wineries characterized by high-vol-
\end{abstract}

Correspondence: Roberto Beghi, Department of Agricultural and Environmental Sciences - Production, Landscape, Agroenergy, Università degli Studi di Milano, via Celoria 2, 20133, Milano, Italy.

E-mail: roberto.beghi@unimi.it

Key words: Industry 4.0; automation; yeast; energy; life cycle assessment; sustainability.

Acknowledgements: the authors wish to thank Dr. Fabrizio Ghinolfi and HTS Enologia for the important and qualified contribution.

See online Appendix for supplementary materials.

Received for publication: 6 June 2021.

Accepted for publication: 17 September 2021.

${ }^{\circ}$ Copyright: the Author(s), 2021

Licensee PAGEPress, Italy

Journal of Agricultural Engineering 2021; LII:1213

doi:10.4081/jae.2021.1213

This article is distributed under the terms of the Creative Commons Attribution Noncommercial License (by-nc 4.0) which permits any noncommercial use, distribution, and reproduction in any medium, provided the original author(s) and source are credited. ume tanks, where scale factor played a crucial role. Nutrients used by the automated system are more expensive but more environmentally sustainable than traditional ones.

\section{Introduction}

Automation in viticulture and oenology chains is becoming a crucial key aspect. The necessity of automation in industrial processes is due to the organization's need to lead towards competitive advantages such as quality improvement, productivity, and increasing profits (Caldwell, 2012).

Productivity is directly related to efficient use and management of input resources, which can be improved both in terms of processing rate and waste reduction by automation and optimization. Optimization allows the improvement and standardization of the product quality and its monitoring in a simplified way during the entire process, by sensory applications that work in online/real-time mode, to facilitate subsequent correction measures (Caldwell et al., 2009).

Precision viticulture aims to maximize the oenological potential of vineyards. The introduction of new technologies for supporting the vineyard management system (Oberti et al., 2013) allows increased efficiency and production quality, coupled to a reduction of the environmental impact (Matese and Di Gennaro, 2015). In the oenology process, several automated methods have been proposed for online fermentation monitoring. However, the need for computer technologies and sensors has made these strategies challenging to implement in a real scale context. As a result, few industrial fermentations are currently monitored online, but this condition should be overcome soon (Sablayrolles, 2009).

The possibility of a rapid and automated monitoring system of oenological parameters allows winery operators to intervene in a targeted way on the production process, leading effectively to the desired goal. Nevertheless, this is not easy to reach in winemaking because of the variability of grapes (Xiao-yu et al., 2007; Alem et al., 2019). The implementation of a real-time/online check has allowed the development of automatic systems that can be used remotely to manage oenological processes (Caldwell et al., 2009).

The increasingly heightened use of both automation and integrated systems is shaping the development of the fourth step of industrialization called Industry 4.0 (Vaidya et al., 2018). This latest industrial revolution is enabled by the development of information and communication technologies (ICT), with its technological basis in intelligent automation (Rojko, 2017). The key to this progress is the combination of plants with great technological potential and the information systems responsible for their operation and control. The terms connection and cyber-physical systems 
(CPS) mean physical systems (machines and systems) integrated with computers capable of relating to other CPS by identifying the new concept of smart factory (Tugnolo et al., 2018). CPSs operate in a self-organized and decentralized way, based on sensor systems applied to obtain data and actuators to physically influence the process (Stock and Seliger, 2016). Processes implemented with these elements enable profit increase even more by Organizations, as they adopt strategies such as lean production, just in time production, and outsourcing production. In this context, Industry 4.0 reduces production, logistics, and quality management costs from 10 to $30 \%$ (Rojko, 2017). This reduction is clear compared to Industry 3.0, where the applied technologies can be limited because man is still responsible for actions that do not add value and may be a source of error (Tugnolo et al., 2018).

Compared to previous automated productions, systems in compliance with Industry 4.0 are then even more capable of safeguarding and optimizing energy and resources consumption, leading to the development of operating units that are increasingly sustainable from an environmental and an economic point of view (Burritt and Christ, 2016; Stock, Seliger, 2016).

The wine industry is certainly in the process of technological modernization driven by the Industry 4.0 approach (Sá et al., 2020). Fermentation is one of the most critical processes for grape musts. It consists of an exothermic microbial bioconversion reaction, in which the yeast $S$. cerevisiae from 1 mole of glucose produces 2 moles of ethanol and $\mathrm{CO}_{2}: \mathrm{C}_{6} \mathrm{H}_{12} \mathrm{O}_{6}(180 \mathrm{~g}) \rightarrow 2 \mathrm{C}_{2} \mathrm{H}_{4} \mathrm{OH}$ $(92 \mathrm{~g})+2 \mathrm{CO}_{2}(88 \mathrm{~g})+138 \mathrm{~kJ}$ (Nardin et al., 2006). The quality of the finished product depends on this process.

For a successful winemaking operation, the control of all alcoholic fermentation parameters is essential. The aim is the optimization of the product quality, which is difficult to establish and quantify. Research has shown that the faster the fermentation, the poorer the quality of the wine is, especially for white wines. On the contrary, fermentation which takes too long times increases the risk of off-flavours development and leads to possible damage to the aromatic profile of the wine (Sablayrolles, 2009). Fermentation kinetics management is considered a prerequisite to controlling wine properties (Suzzi and Tofalo, 2018). Despite the technological advances made in fermentation and the energies that oenologists devote to this critical phase to control quality parameters and perform optimization continuously, blocked or poorly conducted processes can still develop with a high economic impact for wineries (Sablayrolles, 2009).

This work aimed to analyse a system for the automated management of yeast nutrition in alcoholic fermentation compared to the traditional fermentation management approach. The evaluation was carried out considering electricity consumption, use of raw materials, operation time control related to the manpower for the winery workers, and fermentation cycles. Moreover, the life cycle assessment (LCA) methodology and cost analysis have been applied to evaluate the environmental and economic performance of the traditional and automated systems.

\section{Materials and methods}

\section{The automated system}

Avaferm ${ }^{\circledR}$ system is a transportable automated, easily installable, and place and start system for automated management of yeast nutrition in oenological alcoholic fermentation. This system is made by HTS Enologia (Trapani, Italy) with patent $\mathrm{N}^{\circ}$
IT201900001239A1 (2019). The system is equipped with a control unit and rods for the nutrients dosage, and it works with a memory unit in which fermentative kinetics curves are loaded. The curves are predefined or customized according to oenologists' needs.

The system starts working when fermentation is activated with must having ethanol values of about $1 \% \mathrm{vol} / \mathrm{vol}$. At this point, winemaker or winery operators connect the dosing rods to the fermentation tanks. Thanks to the control unit, the starting parameters related to the process are entered. Then, the fermentation is carried out based on desired must (and wine) characteristics to be reached, such as type of must and volume, sugar concentration, readily usable nitrogen, type of yeast, fermentation temperature, and oenological objective. The automated system responds by proposing a fermentative kinetic curve, according to a so-called 3Q model (Which, How much, When). The model identifies which organic or inorganic nutrient to add (Viniliquid, DAP liquid, and oxygen), quantity, and at what times of the fermentation process.

\section{Experimental plan}

For this study, fermentation in real industrial scale winery plants was considered. In addition, the unitary operation of alcoholic fermentation was subjected to direct monitoring at the following wineries: Borgo Molino Vigne \& Vini Treviso, Italy (BM) with about $10 \times 10^{6} \mathrm{~kg}$ of grapes pressed per year (different varieties for sparkling wine) and Cantina Forlì Predappio Soc. Agricola Coop Forlì Cesena, Italy (FP) with about $60 \times 10^{6} \mathrm{~kg}$ of grapes pressed per year (different varieties, mainly thermovinificated must).

During the 2020 grape harvest season, fermentations were set up at the production sites to compare the two methods: traditional fermentation management with manual yeast nutrition and fermentation management using the automated system.

At BM, fermentation of white grape must, Vitis vinifera L. cv. 'Glera', was monitored in cement tanks: one process following the traditional method (tank C18) and two using an automated system (tanks C3, C17), with normalized tank volumes at $58 \times 10^{3} \mathrm{~L}$ and filling at $54 \times 10^{3} \mathrm{~L}$. As a result, the selected fermentations were homogeneous in terms of the type of must, type of yeast, and duration of the fermentation process.

At FP, four fermentations of black grape must, Vitis vinifera L. cv. 'Sangiovese' in stainless steel tanks were analysed similarly: two traditional (tank 151 and 158) and two controlled by the automated systems (tank 161a and 161b). In this case, all fermentation tanks had a volume of $153.6 \times 10^{3} \mathrm{~L}$, containing $135 \times 10^{3} \mathrm{~L}$ of must.

The monitoring operation was carried out collecting data of the following parameters: process timing, manpower, nutrients, oxygen, water, and energy consumption. Moreover, during monitoring activities, interviews were conducted with the wineries staff to collect useful additional information for the study.

All evaluations performed were used as inputs for comparing an average tank operated by an automated system and an average tank managed according to the traditional method. These criteria were also applied to the LCA methodology.

\section{Data processing methods of the evaluated parameters}

Benefits (\%) deriving from the use of the automated system or traditional method for each evaluated parameter were calculated according to Equation 1:

$$
R \%=\frac{\text { Value } \min }{\text { value } \max } * 100 ; \text { Benefit } \%=100-R \%
$$

where: value $\min =$ minimum average value for the automated or 
traditional method; value $\max =$ maximum average value for the automated or traditional method.

Consumption (or use) was then related to individual days of usage during the fermentation processes, obtaining comparable graphic trends.

The solid fraction of liquid nutrients formulations (Viniliquid and DAP liquid) was considered the quantity used. This enables the normalization of the used quantities (active ingredient) of nutrients marketed in the fluid state with the quantities of solid ones (to be dissolved in water). DAP liquid by HTS Enologia is composed of bibasic phosphate ammonium in 50\% aqueous solution, while Viniliquid by HTS Enologia is a partial autolysate yeast at $60 \%$ in aqueous solution. The amount of nutrients used is calculated as shown in Equation 2:

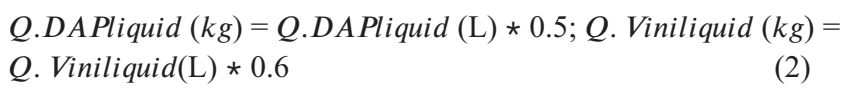

The liquid part present in the oenological products is part of water consumption assessment, and it is calculated as shown in Equation 3:

$\mathrm{H}_{2} \mathrm{O}$ DAPliquid $(\mathrm{L})=Q . D A P l i q u i d(\mathrm{~L}) * 0.5 ; \mathrm{H}_{2} \mathrm{O}$ Viniliquid $(\mathrm{L})$

$=Q$. Viniliquid $(\mathrm{L}) \star 0.4$

\section{Energy consumption evaluation}

The energy consumed by utilities was calculated as shown in Equation 4:

$E(k W h)=P(k W) * t(h) * U$

where: $\mathrm{E}(\mathrm{kWh})=$ absorbed energy; $\mathrm{P}(\mathrm{kW})=$ nominal power load; $\mathrm{t}(\mathrm{h})=$ usage time; $\mathrm{U}=$ coefficient of utilization $(0.9,1$ in case of nominal power load $<2 \mathrm{~kW}$ ).

Concerning the automated system, data on instantaneous current intensity (A), power supply voltage (V), and timing (h) during active dosages and standby machine periods were registered directly by the system. The total energy $\left(\mathrm{E}_{\mathrm{tot}}\right)$ consumed by the machine was calculated according to equations 5-7:

$E_{\text {tot }}(\mathrm{kWh})=E_{\text {dosage }}(\mathrm{kWh})+E_{\text {stanby }}(\mathrm{kWh})$

$E_{\text {dosage }}(k W h)=\sum I_{i d}(A) * V_{d}(V) * t_{d}(h)$

$E_{\text {stanby }}(k W h)=I_{S}(A) * V_{S}(V) * t_{I D L E}(h) / 6$ with: $\mathrm{I}_{\mathrm{id}}=$ dosage instantaneous current intensity; $\mathrm{I}_{\mathrm{S}}=$ stand-by current intensity; $\mathrm{V}_{\mathrm{d}}=$ dosing supply voltage; $\mathrm{V}_{\mathrm{s}}=$ stand-by power supply voltage; $t_{d}=$ dosing time; $t_{I D L E}=$ stand-by time.

The energy consumed by the standby system was divided by 6 . This divisor is equal to the number of Automated system rods that can dose at the same time.

The standby time was calculated according to Equations 8:

$t_{I D L E}(h)=t_{\text {tot }}(h)-t d_{\text {tot }}(h)$

with: $t_{\text {tot }}=$ total processing time; $\mathrm{td}_{\mathrm{tot}}=$ total dosing time.

The two wineries worked differently to estimate the energy consumption of the refrigeration systems.

At BM, the heat exchange between must $\left(17^{\circ} \mathrm{C}\right)$ and the closed outdoor environment $\left(18-20^{\circ} \mathrm{C}\right)$ in which the tanks are located was considered negligible. The heat removed from the must is assumed exclusively equal to that developed by fermentation: $1 \mathrm{~g}$ sugar $=$ $0.13 \mathrm{kcal}$ (Nardin et al., 2006). For this purpose, the chemical analyses reported in Supplementary Table 1 were considered, and tank $\mathrm{C} 17$ was assumed to be equal to $\mathrm{C} 3$.

Knowing the sugar concentration of the pre-fermentation must (g/L), Equation 9 was applied:

$Q_{e}(k c a l)=C_{S}(g / L) * V(L) * E_{f}(k c a l / g)$

where: $\mathrm{Q}_{\mathrm{e}}=$ heat to be removed from the evaporator $(\mathrm{kcal}) ; \mathrm{C}_{\mathrm{s}}=$ concentration in sugar must $(\mathrm{g} / \mathrm{L}) ; \mathrm{V}=$ must volume $(\mathrm{L}) ; \mathrm{E}_{\mathrm{f}}=$ fermentation energy $(0.13 \mathrm{kcal} / \mathrm{g})$.

Tanks are cooled using 4 radiant steel plates immersed in the must, in which circulates cold water (plate size $=0.6 \mathrm{~m}$ wide $\times 1.5$ $\mathrm{m}$ high). A refrigerant distribution efficiency $\left(\eta_{\mathrm{d}}\right)$ of 0.85 , a refrigerator efficiency coefficient $(\varepsilon)$ of 3.5 , a compressor electric motor efficiency $\left(\eta_{\mathrm{e}}\right)$ of 0.9 , a mechanical compressor efficiency $(\eta \mathrm{m})$ of 0.7 , and a compressor usage time $\left(\mathrm{t}_{\mathrm{c}}\right)$ of $12 \mathrm{~h}$ were then assumed.

The energy consumption of the compressor was calculated according to equation 10 :

$Q_{e} C=Q_{e} \eta_{d} ; W=Q_{e} C / \varepsilon ; P_{c}=W /\left(\eta_{e}{ }^{*} \eta_{m}\right) ; E_{c}=P_{c}{ }^{*} t_{c}$

where: $\mathrm{Q}_{\mathrm{e}} \mathrm{C}=$ heat to be removed, considering the distribution losses; $\mathrm{W}=$ work done by the compressor; $\mathrm{P}_{\mathrm{c}}=$ compressor power load; $\mathrm{E}_{\mathrm{c}}=$ energy absorbed by the compressor.

For FP, the same assumptions and calculations were made about the heat produced by fermentation of black grape must $\left(17.5^{\circ} \mathrm{C}\right)$, considering, in this case, a non-isolated system, in which

Table 1. Input data for energy at Borgo Molino Vigne \& Vini Treviso, Italy.

\begin{tabular}{|c|c|c|c|c|}
\hline \multirow{2}{*}{$\begin{array}{l}\text { Electrical utilities } \\
\text { Traditional system }\end{array}$} & \multicolumn{4}{|c|}{ Energy consumption } \\
\hline & Power (kW) & Utilization coefficient & Time (h) & Energy (kWh) \\
\hline Ragazzini pump, $\mathrm{P}=6.5 \mathrm{~kW}\left(1^{\circ}\right.$ gear $), 7.5 \mathrm{~kW}\left(2^{\circ}\right.$ gear $)$ & 7.5 & 0.9 & 3 & 20.25 \\
\hline Liverani pump INV BS, $\mathrm{P}=1.5 \mathrm{~kW}$ & 1.5 & 0.9 & 0.33 & 0.45 \\
\hline Tebaldi oxygenator Microox, $\mathrm{P}=45 \mathrm{~W}$ & 0.045 & 1 & 48 & 2.16 \\
\hline Refrigeration system $750,000 \mathrm{Fr}$ & & & & 315.99 \\
\hline Automated system & Power (kW) & Utilization coefficient & Time (h) & Energy (kWh) \\
\hline Ragazzini pump, $\mathrm{P}=6.5 \mathrm{~kW}\left(1^{\circ}\right.$ gear $), 7.5 \mathrm{~kW}\left(2^{\circ}\right.$ gear $)$ & 7.5 & 0.9 & 2.95 & 19.91 \\
\hline Liverani pump INV BS, $\mathrm{P}=1.5 \mathrm{~kW}$ & 1.5 & 0.9 & 0.36 & 0.49 \\
\hline Automated system & & & & 2.52 \\
\hline Refrigeration system $750,000 \mathrm{Fr}$ & & & & 335.22 \\
\hline
\end{tabular}


stainless steel fermenters are placed outside and exposed to environmental temperatures, obtained by the weather forecast.

A simplification was carried out to estimate heat exchanges between the must and the environment outside the tank. A heat exchange was assumed by conduction in a flat wall through the two constituting materials: stainless steel $\left(15 \mathrm{~W} / \mathrm{m}{ }^{\circ} \mathrm{C}\right)$ and expanded polyurethane $\left(0.022 \mathrm{~W} / \mathrm{m}{ }^{\circ} \mathrm{C}\right)$, with estimated thicknesses of respectively $2 \mathrm{~mm}$ and $80 \mathrm{~mm}$. A global heat exchange coefficient and the amount of heat exchanged were calculated based on Equations 11:

$$
K=\frac{1}{\frac{s 1}{k 1}+\frac{s 2}{k 2}} ; Q=K A\left(T_{i}-T_{o}\right)
$$

where: $T_{i}=$ temperature inside the tank (must + head space); $T_{0}=$ outdoor temperature; $\mathrm{A}=$ heat exchange area of the tank.

As surface available for heat exchange, the side surface and the base area of a cylinder were considered as the closest geometric figure to the fermentation tanks (Equation 12). The base area of the cylinder in contact with the ground has been excluded as a further simplification:

$A=S_{\text {lateral }}+S_{\text {base }} ; S_{\text {lateral }}=2 \pi r h ; S_{\text {base }}=\pi r^{2}$

The total heat that the refrigeration system must remove from FP was calculated based on Equation 13:

$$
Q_{t o t}=Q_{e}+Q
$$

Subsequently, as with BM, the energy absorbed by the compressor (Ec) was calculated cumulatively during the entire fermentation process. At FP, it was also necessary to consider a cooling from $20^{\circ} \mathrm{C}$ to $17^{\circ} \mathrm{C}$ that took place on the must present in the fermentation base on the first day of the process. The heat to be subtracted $\left(\mathrm{Q}_{\mathrm{r}}\right)$ in this case is equal to (Equation 14):

$Q_{r}=m^{*} C_{p} * \Delta T$

where: $m(k g)=V(l) * \rho\left(\frac{k g}{L}\right)$ or mass in process; $\rho=$ must density $(1.050 \mathrm{~kg} / \mathrm{L}) ; \mathrm{c}_{\mathrm{p}}=$ specific heat $\left(0.855 \mathrm{kcal} / \mathrm{kg}^{* \circ} \mathrm{C}\right) ; \Delta \mathrm{T}=$ temperature difference.

Cooling energy absorbed by the compressor was also calculated in this case (Equation 10).

For both production sites, the total consumption of the two refrigeration plants was added to those of the other electrical utilities (E) supporting alcoholic fermentation.

\section{Life cycle assessment}

To compare the environmental impact of the automatic management of yeast nutrition in alcoholic fermentation with the traditional fermentation management approach, the LCA analysis was performed in accordance with international ISO 14040 and 14044 standards (ISO 14040, 2006; ISO 14044, 2018).

\section{Functional unit}

The comparative analysis implies the same functional unit for the two systems analysed. In this study, the functional unit was represented by one average process of alcoholic fermentation conducted with the traditional method and automated system.
Considering the different capacities of the fermentation tanks, at $\mathrm{BM}$, the functional unit refers to an average process of alcoholic fermentation in a $58 \times 10^{3} \mathrm{~L}$ tank, while at FP, an average process of alcoholic fermentation in a $153.6 \times 10^{3} \mathrm{~L}$ tank.

\section{System boundaries}

A 'gate-to-gate' approach was chosen for LCA analysis. The system's boundaries are related to the production of all the ingredients necessary for the unit operation of alcoholic fermentation and range from the activation of yeast and filling of fermentation tanks to first pouring, racking, and cleaning of the equipment. The grape cultivation activities and the transformation into must were considered out of the scope of the study and therefore out of the system's boundaries.

\section{Definition of the product system}

The analysed processes were shown in Supplementary Figures 1 and 2 for BM and FP, respectively. It is important to highlight that at the start of fermentation (about 1 degree of alcohol), the differentiation between traditional and automated management occurs, respectively highlighted in orange and green in the figures.

\section{Inventory analysis (LCI)}

The inventory analysis was carried out with the primary data collected with the monitoring activities and made it possible to identify the resources used at BM and FP for each phase of the production and fermentation processes (Tables 1-2 and Supplementary Tables 2-8). Supplementary Table 8 presents the percentage compositions of the oenological products used in the two wineries.

In the LCA study, the volumetric dosages of automated system liquid nutrients were multiplied by the density of the values equal to $1.1 \mathrm{~kg} / \mathrm{L}$ and $1.3 \mathrm{~kg} / \mathrm{L}$, respectively, obtaining the total mass value $(\mathrm{kg})$.

\section{Missing data}

The lack of information for some fermentation inputs determined their exclusion from LCA analysis. Constituent materials of machine instrumentation were excluded from the study due to the lack of detailed information and the possibility of reliable estimates.

In addition, sulphite musts, tannins used at FP (grape seed tannin and tan fermcolor), and stab micro-M (ENARTIS) oenological products were excluded from the study due to the lack of detailed information. Following interviews with FP staff, DESO2, Vitamon $\mathrm{CE}$, and Fermaid E oenological products were considered equivalent to Nutristart.

\section{Impact assessment}

For the impact assessment, the CML-IA non-baseline method (acidification) and CML-IA baseline method (eutrophication, global warming, ozone layer depletion, and abiotic depletion, elements, and fossil fuels), water scarcity category based on AWARE method, and Photochemical oxidation based on ReCiPe 2008 were used. The eight impact categories are: Acidification (fate not incl.) ( $\mathrm{kg} \mathrm{SO}_{2}$ eq); Eutrophication ( $\left.\mathrm{kg} \mathrm{PO}_{4} \mathrm{eq}\right)$; Global warming (GWP100a) (kg CO 2 eq); Photochemical oxidation (kg NMVOC); Abiotic depletion, elements ( $\mathrm{kg} \mathrm{Sb}$ eq); Abiotic depletion, fossil fuels (MJ); Water scarcity ( $\mathrm{m}^{3} \mathrm{eq}$ ); Ozone layer depletion (ODP) (optional) (kg CFC-11 eq). The LCA was developed using SimaPro software (version 9.1). 


\section{Cost analysis}

The cost analysis follows the LCA approach, with the same system boundaries, product system, and aim of the analysis shifted to the economic field. However, the amortization costs of the plants and the end-of-life costs were excluded, considering only the portion of variable costs weighting on the studied processes.

Regarding the inventory phase, all the input materials of the considered system refer to their monetary cost $(€)$. The allocated costs divided among the studied parameters (manpower, oenological products, oxygen, water consumption, energy consumption), considered variable costs, were summed up for the two different analysed methodologies of fermentation management to obtain a numerical comparison. Finally, an attempt was made to quantify the advantage of shorter process times in terms of costs and a payback period for the automated instrumentation. For this purpose, a grape harvest of 60 days, 6 traditionally managed tanks, and 6 automated ones were considered, as the automated system has an equal number of rods that can dose at the same time. Furthermore, the extra potential fermentation cycles achievable through an automated system were counted as cost savings.

The payback period for the two wineries was calculated as shown in Equations 15-18:

Cost total $T=$ Cost 6 tank $T *$ Batches $T\left(\frac{\text { tank }}{\text { harvest }}\right)$

$$
\text { Cost total } A=\operatorname{Cost} 6 \operatorname{tank} A * \text { Batches } A\left(\frac{\text { tank }}{\text { harvest }}\right) \text { with savings }
$$

Savings Avaferm $=$ Cost total $T-$ Cost total A

Payback $($ years $)=\frac{\text { Cost Avaferm system }(€)}{\text { Savings } \operatorname{Avaferm~}(\epsilon)}$

where the cost of the automated system $=48,000 €, T=$ traditional system, $\mathrm{A}=$ automated system.

\section{Results and discussion}

\section{Fermentation timing}

Timelines were drawn to analyse process times for the monitored fermentations (Supplementary Figures 3-6).

Compared to traditional management, the automated system enabled a reduction in fermentation times (Table 3 ) of $31 \%$ at BM and $12.5 \%$ at $\mathrm{FP}$, with the possibility of carrying out 1.75 and 0.5 extra fermentation cycles per tank/grape harvest (assumed equal to 60 days). However, this is possible if additional grape material is available and if it is part of the company's marketing choices. Otherwise, the winemaker will have a free tank available to pour batches of wine for the corresponding duration of fermentation,

Table 2. Input data: energy for Cantina Forlì Predappio Soc. Agricola Coop Forlì Cesena, Italy.

\begin{tabular}{|c|c|c|c|c|}
\hline \multirow{2}{*}{$\begin{array}{l}\text { Electrical utilities } \\
\text { Traditional system }\end{array}$} & \multirow[b]{2}{*}{ Power (kW) } & \multicolumn{2}{|c|}{ Energy consumption } & \multirow[b]{2}{*}{ Energy (kWh) } \\
\hline & & Coeff. of utilization & Usage time (h) & \\
\hline Yeasts activator, Reactivator $60 \mathrm{AEB}$ Engineering, $\mathrm{P}=8 \mathrm{~kW}$ & 8 & 0.9 & 3 & 21.60 \\
\hline 2 Pumps Ragazzini, $\mathrm{P}=6.5 \mathrm{~kW}\left(1^{\circ}\right.$ gear $), 7.5 \mathrm{~kW}\left(2^{\circ}\right.$ gear $)$ & 7.5 & 0.9 & 13 & 87.75 \\
\hline Mixer Cadalpe, $\mathrm{P}=4 \mathrm{~kW}$ & 4 & 0.9 & 1.23 & 4.43 \\
\hline Resin Stabtar ever, $\mathrm{P}=2.3 \mathrm{~kW}$ & 2.3 & 0.9 & 1 & 2.07 \\
\hline Refrigeration system, 1 group $=2,000,000 \mathrm{Fr}$ & & & & $27,682.38$ \\
\hline Automated system & Power (kW) & Coeff. of utilization & Usage time (h) & Energy (kWh) \\
\hline Yeasts activator, Reactivator 60 AEB Engineering, $\mathrm{P}=8 \mathrm{~kW}$ & 8 & 0.9 & 3 & 21.60 \\
\hline 2 Pumps Ragazzini, $\mathrm{P}=6.5 \mathrm{~kW}\left(1^{\circ}\right.$ gear $), 7.5 \mathrm{~kW}\left(2^{\circ}\right.$ gear $)$ & 7.5 & 0.9 & 11.66 & 78.71 \\
\hline Mixer Cadalpe, $\mathrm{P}=4 \mathrm{~kW}$ & 4 & 0.9 & 0.615 & 2.21 \\
\hline Resin Stabtar ever, $\mathrm{P}=2.3 \mathrm{~kW}$ & 2.3 & 0.9 & 1.25 & 2.59 \\
\hline Automated system & & & & 3.52 \\
\hline Refrigeration system, 1 group =2,000,000 Fr & & & & $25,151.12$ \\
\hline
\end{tabular}

Table 3. Average values of the evaluated parameters in the wineries.

\begin{tabular}{|c|c|c|c|c|}
\hline Evaluated parameters & $\begin{array}{c}\text { BM } \\
\text { Traditional }\end{array}$ & $\begin{array}{c}\text { FP } \\
\text { Automated }\end{array}$ & Traditional & Automated \\
\hline Type of must & \multicolumn{2}{|c|}{ Glera } & \multicolumn{2}{|c|}{ Sangiovese } \\
\hline Volume of most $\left(10^{2} \mathrm{~L}\right)$ & \multicolumn{2}{|c|}{540} & \multicolumn{2}{|c|}{1350} \\
\hline Fermentation timing (gg) & 16 & 11 & 16 & 14 \\
\hline Manpower $\left(\mathrm{min} / 10^{2} \mathrm{~L}\right)$ & 0.496 & 0.407 & 0.266 & 0.356 \\
\hline Nutrients $\left(\mathrm{kg} / 10^{2} \mathrm{~L}\right)$ & 0.057 & 0.061 & 0.058 & 0.070 \\
\hline Oxygen $\left(\mathrm{g} / 10^{2} \mathrm{~L}\right)$ & 0.60 & 0.89 & 2.10 & 4.51 \\
\hline Water $\left(\mathrm{L} / 10^{2} \mathrm{~L}\right)$ & 27.70 & 27.48 & 13.48 & 12.95 \\
\hline Energy excluding refr. system $\left(\mathrm{kWh} / 10^{2} \mathrm{~L}\right)$ & 0.042 & 0.042 & 0.086 & 0.089 \\
\hline Energy tot $\left(\mathrm{kWh} / 10^{2} \mathrm{~L}\right)$ & 0.63 & 0.66 & 20.59 & 18.71 \\
\hline
\end{tabular}

BM, Borgo Molino Vigne \& Vini Treviso, Italy; FP, Cantina Forlì Predappio Soc. Agricola Coop Forlì Cesena, Italy. 
facilitating the winery management. The shorter process timing is due to the ability of the automated system to distribute yeast nutrients in real-time when necessary and in adequate quantities, based on the dosage curves preloaded in the machine and then implemented, keeping the fermentation activity high at the optimum level.

\section{Manpower}

Considering the overall fermentation processes, it was found that automation allows a reduction in manpower of $18 \%$ to $\mathrm{BM}$ and $25 \%$ to FP. In FP, processes are more complex, and the advantages produced using the automated system tend to be enhanced compared to those obtained for a medium-scale winery as BM. Figure
1 shows manpower trends in the two wineries.

The lower use of manpower allows the reduction of production costs and facilitates winery activities that become less susceptible to human failure, an element of variability that causes a lower capacity of the processes to produce within the specified tolerances. Subjectivity in the operations carried out by the winery operators weighs both the quality of the products and profits (Rodríguez-Pérez, 2019).

\section{Nutrients and oxygen}

The analysis of nutrients and oxygen use (Table 3 ) and related trends (Figure 2) during fermentation was crucial because the introduction of nutrients to the must in order to support and con-
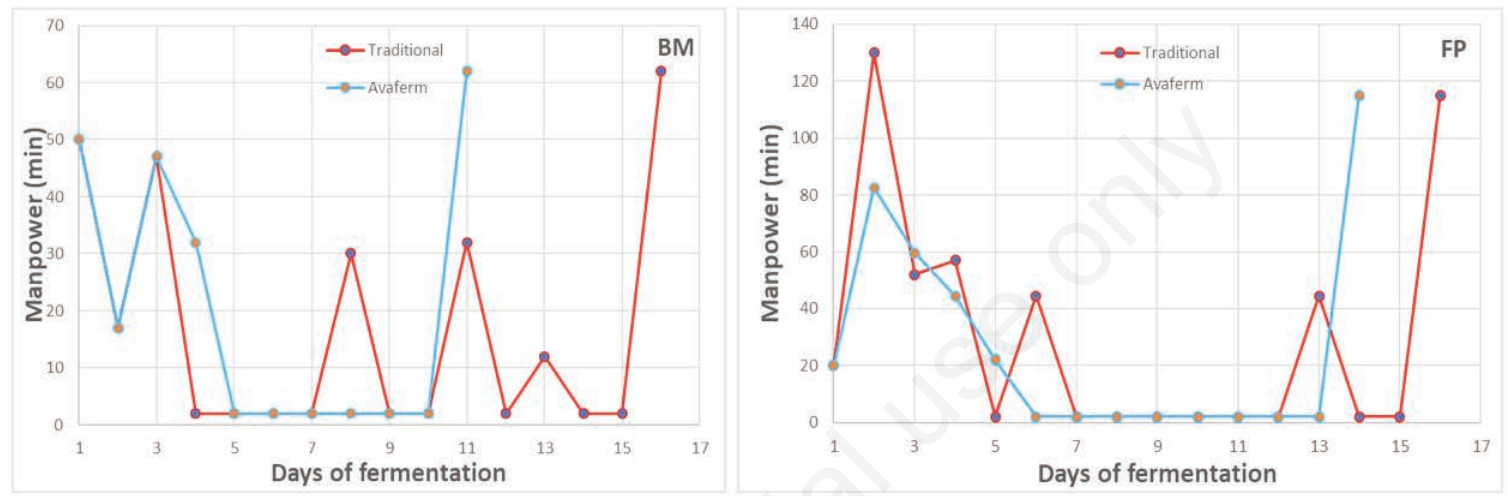

Figure 1. Average trends in manpower: traditional (red) vs automated (blue) systems at Borgo Molino Vigne \& Vini Treviso, Italy (BM) (left) and Cantina Forlì Predappio Soc. Agricola Coop Forlì Cesena, Italy (FP) (right).
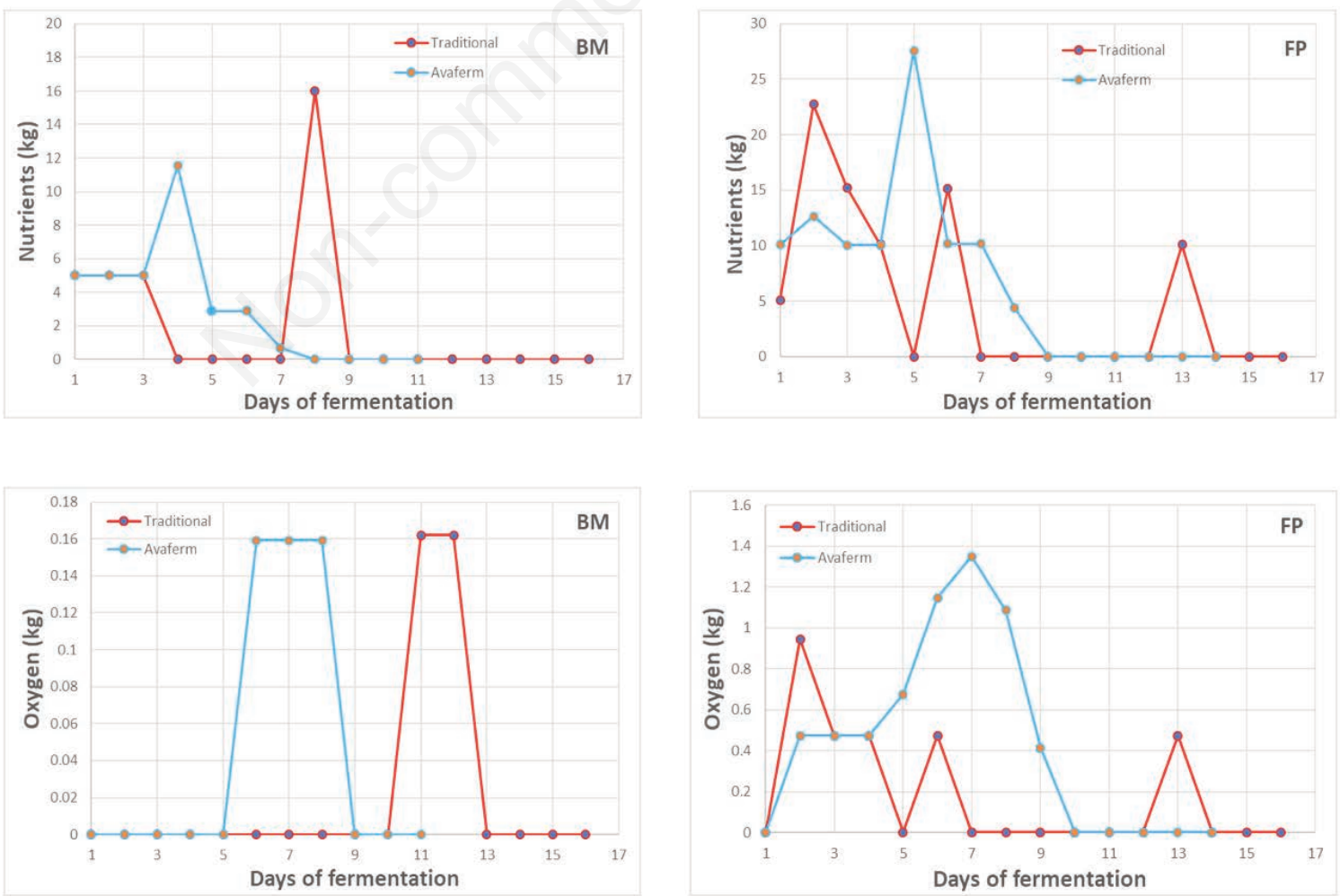

Figure 2. Average trends in nutrients and oxygen: traditional (red) vs automated (blue) systems at Borgo Molino Vigne $\&$ Vini Treviso, Italy (BM) (left) and Cantina Forlì Predappio Soc. Agricola Coop Forlì Cesena, Italy (FP). 
duct yeast metabolism is the main goal of the automated system. The use of organic and inorganic nutrients was almost similar between traditional management and automated system management at BM. At FP, the automation system uses $17.5 \%$ more of the considered resource. In the same way, the greater use of resources with automated system management also emerged for oxygen, $32 \%$ higher at BM and $53.5 \%$ higher at FP. The total amount donated through automated dispensers and reassembling is considered, regarding a value of $7 \mathrm{mg} / \mathrm{L}\left(\mathrm{O}_{2} /\right.$ remontage $)$, as reported by Ribèreau-Gayon et al., 2017. These values depend on the fact that with the traditional management system, it is not always possible to provide the yeast with an adequate amount of nutrients: therefore, the microorganism often tends to nutritional deficiency, responsible for any off-flavours and slows down and sometimes blocks processes (Bely et al., 1990; Bell et al., 2005; RibèreauGayon et al., 2017). These assumptions are supported by shorter process times previously highlighted for the automated system.

Finally, nutrient addition carried out with the traditional method is a pretty tricky procedure; operators could pay attention to avoid human errors during dosage operation. However, these difficulties do not occur when an automated system is used, guaranteeing the yeast the essential nutrients for maintaining an optimal metabolic activity based on the set curves.

\section{Water consumption}

Water consumption is an essential factor to be considered in managing winery resources: in Europe, wineries use water in average quantities of $5 \mathrm{~L}$ for each litre of wine. These amounts are mainly correlated to virtuous behaviour. In general, the use of water resources decreases proportionally with the growth machinery size considered (Lamastra, Trioli, 2014; Trioli et al., 2015).

Water consumption (Table 3) was lower with the Automated system in $0.8 \%$ and $3.9 \%$ at BM and at FP, respectively. The savings are due to the unnecessary process of: i) oenological products dissolution before feeding them in the tank (carried out in BM); and ii) cleaning operation of the fermentation support equipment. These operations are mostly carried out at FP, where the fermentation support utilities are present in more significant numbers and where an external mixer is used to dissolve nutrients in a part of must taken from fermentation. Nutrients introduced with an automated system are already in a liquid state, and after dosing, the feeding rods do not require to be washed.

\section{Energy consumption}

Concerning energy consumption (Table 3), fermentation support utilities (automated system, yeast activator, pumps, and mixers) were first analysed, excluding refrigeration systems which require specific assessments. Traditional management and the automated one using automated showed the same amounts of energy consumed at BM. At the same time, at FP, where the plant is bigger and where greater demand of electric utilities to support the processes is required, automation implementation saves $4 \%$ of energy demand.

In general, the differences between the energy consumption of traditional and automated management depend on the specific organization of winery activities and the size of the plants.

It should also be pointed out that considering only automated consumption in the two different sized wineries, values are always almost the same. As a result, the automated system suits high-volume fermentation tanks. In fact, at BM automated system uses $0.046 \mathrm{Wh} / \mathrm{L}$ versus $0.026 \mathrm{Wh} / \mathrm{L}$ of $\mathrm{FP}$, with a difference of $43.5 \%$ where the volumes involved are higher.

Energy consumption trends of fermentation support utilities are shown in Figure 3. Energy consumption was also assessed, including refrigeration systems (Table 3) (total energy). The automated management at BM highlighted a $+5 \%$ of the energy consumed, even if the fermentation cycles were shorter. This positive value is due to a better exponential fermentation activation in the tanks managed by an automated system (temperature managed independently from the machine) and to the indoor positioning of the tanks. This allows to neglect the exchanged heat between must and outdoor environment and to consider only the contribution given by the fermentation, with the musts all starting from the same sugar concentration. In best conditions, with fermentation starting from the same day (equal temperature management), there would have been no differences between the two management methods.

At FP, where tanks are outdoor and exposed to uncontrolled ambient temperatures, the heat removed by the refrigeration system equals the heat produced by fermentation and exchanged with the external environment. In this case, the shorter process times enabled $9.1 \%$ energy savings with the automated system. Therefore, the refrigeration unit is used for shorter times, depending on the duration of fermentation.
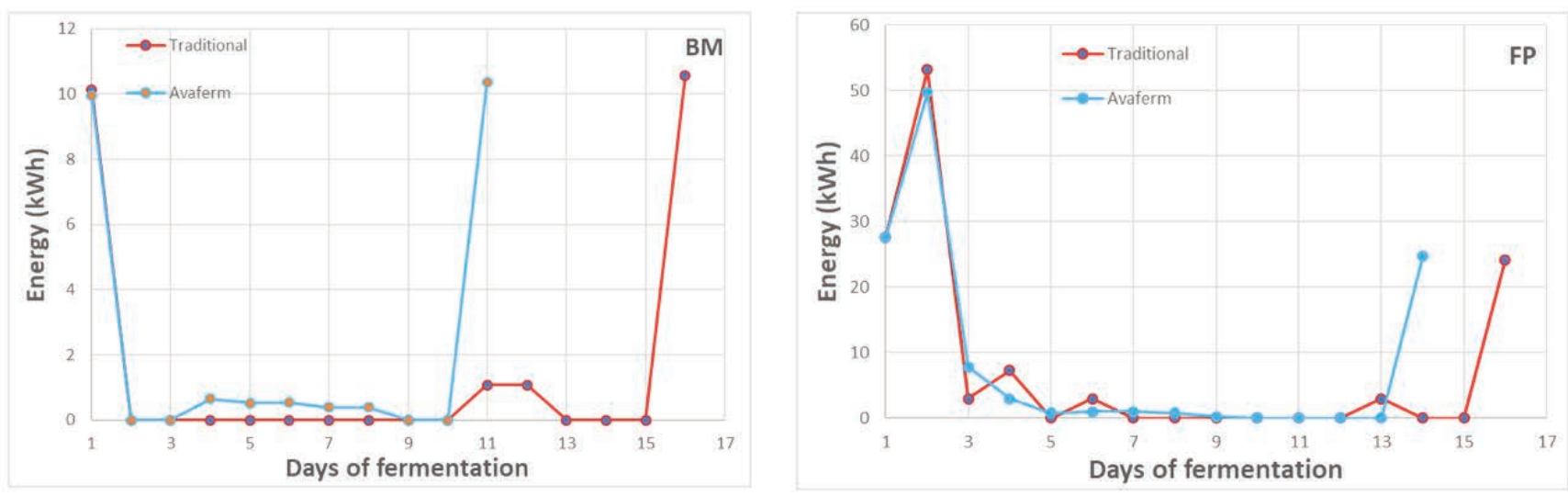

Figure 3. Average trends in energy consumption, excluding refrigeration systems: traditional (red) vs automated (blue) systems at Borgo Molino Vigne \& Vini Treviso, Italy (BM) (left) and Cantina Forlì Predappio Soc. Agricola Coop Forlì Cesena, Italy (FP). 


\section{Results of life cycle assessment analysis}

The comparison between the environmental impact of fermentation carried out with the traditional method and with the automated system at BM is shown in Supplementary Figure 7. Better environmental performance for the processes managed by the automation system can be noticed, $1.75 \%$ less on average among all impact categories analysed (Supplementary Table 9).

The impact categories for which a more significant advantage emerged are abiotic depletion of fossil fuels (3.29\%), ozone depletion $(3.14 \%)$, and photochemical oxidation $(2.05 \%)$.

Regarding BM, the greater environmental sustainability of automated processes is due to the addition of nutrients which differentiates the two management methods and has a lower environmental impact of $32.7 \%$ on average among all impact categories (Supplementary Table 10). Furthermore, based on the results presented in 'Nutrients and oxygen', it can be stated that the lower environmental impact is not due to the amount of nutrients but to the use of the right oenological products for yeast nutrition using the automated system. Considering the differentiation between the processes, the amounts of nutrients are almost the same between the two management methods, as mentioned above.

Considering only the nutrient addition phase and then the global impact, the recovery of the environmental impact gap between the traditional and automated system is due to the low weight of the nutrition operation compared to the total impact and the higher energy consumption the refrigeration system. However, the latter is independent of the automated system but depends on the different exponential fermentation activation.

The environmental impact comparison between traditional management and automated system for FP is shown in Supplementary Figure 8 and Supplementary Table 11. Automated management leads to better environmental performance in this winery with a $7.9 \%$ less on average among all impact categories analysed.

The impact categories with a greater environmental advantage are ozone depletion (9.07\%), abiotic depletion elements $(8.97 \%)$, eutrophication $(8.94 \%)$, water scarcity $(8.87 \%)$, and photochemical oxidation $(8.70 \%)$.

At FP, the lower environmental impact of the automated system compared to the traditional method is due to the lower energy consumption of the refrigeration system, highlighted by the lower duration of the fermentation process by $12.5 \%$.

\section{Results of cost analysis}

Supplementary Table 12 and Supplementary Figure 9 show the results of the variable cost analysis for BM: a $+18.8 \%$ for automated management compared to the traditional one can be detected.

The cost analysis considered a comparison based on one fermentation tank and shows that the item with the most significant impact is nutrients in differentiation, with $47.69 \%$ ( $€ 351$ ) and $58.15 \%$ ( $€ 527.26$ ) for the traditional and for automated management respectively. Moreover, oenological products and preliminary nutrients also showed an enormous difference equal to $36.72 \%$ ( $€ 270.26)$ for the traditional and $29.81 \%$ (€ 270.26) for automated management.

Differentiating nutrients is essential since they refer to the oenological products used during yeast nutrition, distinguishing between traditional management and the automated system. Cost analysis showed that nutrients used for the automated system are $33.42 \%$ more expensive than those used in traditional management, having a more significant impact on total variable costs.

The oenological products previously added to the actual nutri-

\section{Benefits and opportunities}

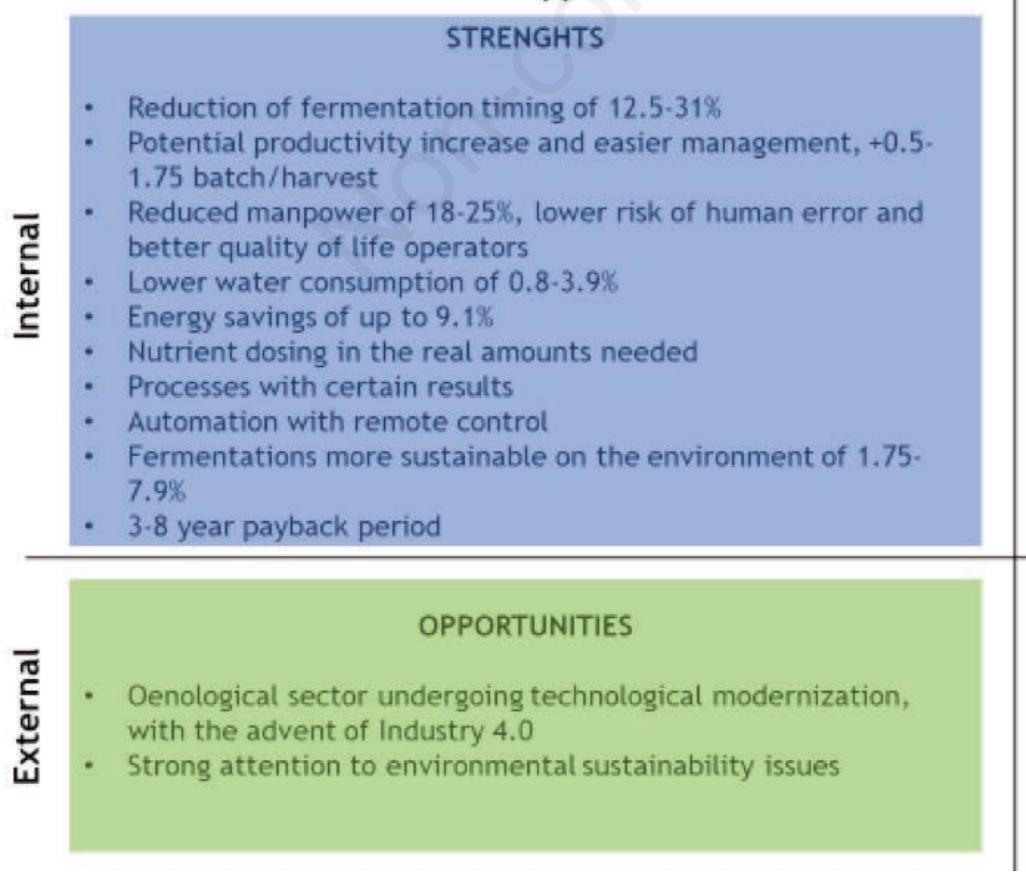

\section{Risk and dangers}

\author{
WEAKNESSES
}

Higher Avaferm nutrient costs of 33.4 . 83.5\% (Viniliquide DAP liquid)

Limited benefits of automation in small wineries

High investment cost for small production sites

Figure 4. SWOT analysis regarding the adoption of the automated system. 
tion phase are the same and of equal cost and are used in the same amount.

In addition, an interesting focus could be done on manpower and energy. Regarding manpower to carry out the fermentation process, 6\% (€ 44.67) and 4\% ( $€ 36.67)$ could be noticed for the traditional management and the automated one, respectively. Energy consumption accounts for $6.67 \%(€ 49.08)$ and $5.67 \%(€$ 51.37) for traditional management and automated ones. Manpower cost item expresses the $18 \%$ advantage also mentioned in Evaluation of parameters obtained from monitoring activities. Electricity costs are mainly guided by the refrigeration system that in $\mathrm{BM}$ consumes more with the automated system than traditional management.

The FP variable costs analysis results are reported in Supplementary Table 13 and Supplementary Figure 10, showing an overall $+1.8 \%$ for automated management. In this case, the highest cost items are energy, oenological products, preliminary nutrient products, and differentiating nutrients. The highest incidence is due to energy with $66.96 \%$ ( $€$ 4006.56) and $60.30 \%$
( $€$ 3676.87) for the traditional and automated management, respectively, derived by the high energy consumption of the refrigeration system and outdoor fermentation tanks. Energy costs are 8.2\% lower in the automated system. Oenological and preliminary nutrient products, independent of the management system and related to the characteristics of processed must, showed greater weights in the traditional system $(27.07 \%, € 1619.61)$ compared to an automated system $(13 \%, € 792.98)$, identifying a cost gap equal to $+51 \%$.

Opposite results emerged for differentiating nutrients which confirm at FP the BM results, identifying as more expensive the oenological products for automated nutrition. An incidence of $4.22 \%$ ( $€ 252.50)$ with traditional management and $25.19 \%$ (€ 1535.88 ) with the automated system can be noticed, accounting for a plus for this cost item equal to $83.5 \%$.

Although its impact on total variable costs is low, it is also worth highlighting manpower of $1.34 \%$ ( $€ 80.17)$ with the traditional management and $0.98 \%$ ( $€ 59.92)$ with the automated system, accounting for a difference for manpower costs of $25 \%$ to the

Table 4. Total variable costs: 6 tank traditional vs 6 tank automated system for Borgo Molino Vigne \& Vini Treviso, Italy.

\begin{tabular}{|c|c|c|c|}
\hline Traditional system 6 tank & Cost $(€)$ & Automated system 6 tank & Cost $(€)$ \\
\hline Manpower & 268 & Manpower & 220 \\
\hline Oenological products and preliminary nutrients & 1621.56 & Oenological products and preliminary nutrients & 1621.56 \\
\hline Nutrients in differentiation & 2106 & Nutrients in differentiation & 3163.58 \\
\hline Oxygen & 3.34 & Oxygen & 4.93 \\
\hline Water & 122.97 & Water & 121.86 \\
\hline Energy & 294.46 & Energy & 308.21 \\
\hline Cost 6 tank & 4416.34 & Cost 6 tank & 5440.14 \\
\hline Cost of unavailability & 0 & Total cost automated system & $10,880.28$ \\
\hline Total cost traditional system & $16,561.270$ & 8 & \\
\hline Batches (tank/harvest) traditional system & $\begin{array}{l}\mathrm{N}^{\circ} \\
3.75\end{array}$ & Batches (tank/harvest) with savings & $\begin{array}{l}\mathrm{N}^{\circ} \\
2.00\end{array}$ \\
\hline \multicolumn{3}{|c|}{ Plus batches (tank/harvest) automated vs traditional system } & 1.75 \\
\hline Savings Automated system $(€)$ & 5681 & & \\
\hline Automated system cost $(€)$ & 48,000 & & \\
\hline \multicolumn{4}{|c|}{$\begin{array}{l}\text { Table 5. Total variable costs: } 6 \text { tank traditional } v s 6 \text { tank automated system for Cantina Forlì Predappio Soc. Agricola Coop Forlì } \\
\text { Cesena, Italy. }\end{array}$} \\
\hline Traditional system 6 tank & Cost $(€)$ & Automated system 6 tank & Cost $(€)$ \\
\hline Manpower & 481.00 & Manpower & 359.50 \\
\hline Oenological products and preliminary nutrients & 9717.63 & Oenological products and preliminary nutrients & 4757.88 \\
\hline Nutrients in differentiation & 1515.00 & Nutrients in differentiation & 9215.26 \\
\hline Oxygen & 0 & Oxygen & 48.19 \\
\hline Water & 149.60 & Water & 143.44 \\
\hline Energy & $24,039.35$ & Energy & $22,061.22$ \\
\hline Cost 6 tank & $35,902.58$ & Cost 6 tank & $36,585.49$ \\
\hline Cost of unavailability & 3.74 & Total cost automated system & $118,902.85$ \\
\hline Total cost traditional system & $134,638.42$ & & \\
\hline Batches (tank/harvest) traditional system & $\begin{array}{l}\mathrm{N}^{\circ} \\
3.75\end{array}$ & Batches (tank/harvest) with savings & $\begin{array}{l}\mathrm{N}^{\circ} \\
3.25\end{array}$ \\
\hline Plus batches (tank/vendemmia) autom & onal & & 0.5 \\
\hline
\end{tabular}

Savings automated system $(€)$

Automated system cost $(€)$

Payback period (years)
15,736 48,000 3 
advantage of the automated system.

Finally, the different process times between traditional and automated management were considered to compare production variable costs in the most realistic way. This led to a payback period value on the costs of the automated system highlighting the investment potential of the analysed instrumentation. The results are proposed in Tables 4 and 5. For BM, a payback period (expressed as savings on production costs) of 8 years could be noticed, and the traditional management shows total variable costs of $€ 16,561.27$ against $€ 10,880.28 €$ using an automated system (i.e., savings equal to $€ 5680.99 €$ ). Regarding FP, a 3-year payback period is calculated, where total variable costs of $€ 134,638$ and $€ 118,903$ (i.e., savings equal to $€ 15,736$ ) are shown for traditional and automated management, respectively.

\section{Conclusions}

Conclusions are presented in the form of a SWOT matrix (Figure 4), which enhances the strengths and weaknesses of the analysed automated system. The differences between the two analysed wineries in terms of size of production sites and the number of wine bottles/volumes produced enabled us to identify a minimum and a maximum variability of the data within is appropriate to place most of the production companies.

Overall, the automated system reveals to be a promising investment, especially if applied to large wineries with high volume tanks, where the advantages given by automation are enhanced. In these production sites, an automated system enables the realization of optimized lean productions by reducing all the resources, except for nutrients which are more expensive than those traditionally used but more sustainable from an environmental point of view.

Furthermore, where the volumes of fermented must per batch are higher, there is also a lower payback period. From this point of view, smaller production sites may have difficulty approaching an automation investment and complying with Industry 4.0 demands.

The significant reduction in manpower is undoubtedly important because it leads to minimization of human failure risk, a better quality of life of workers, cost savings, and a better quality of finished product, thanks to the reduction in process variability. This is also possible through real-time and remote monitoring of alcoholic fermentation and yeast nutrition, leading to more capable processes than those deriving from traditional management and with clear results.

The automated system also allows obtaining more sustainable fermentations from an environmental point of view compared to traditional management.

Finally, automation fits well in a historical oenological context of technological modernization and in a sector increasingly conscious of environmental sustainability issues, although companies (smaller wineries) managed by the old generation are still strongly linked to traditional production methods and not directed at innovation.

\section{References}

Alem H., Rigou P., Schneider R., Ojeda H., Torregrosa L. 2019. Impact of agronomic practices on grape aroma composition: a review. J. Sci. Food. Agr. 99:975-85.
Bell S.J., Henschke P.A. 2005. Implications of nitrogen nutrition for grapes, fermentation and wine. Aust. J. Grape Wine R. 11:242-95.

Bely M., Sablayrolles J.M., Barre P. 1990. Automatic detection of assimilable nitrogen deficiencies during alcoholic fermentation in oenological conditions. J. Ferment. Bioeng. 70:246-52.

Burritt R., Christ K. 2016. Industry 4.0 and environmental accounting: a new revolution?. Asian J. Sustain. Social Respons. 1:23-38.

Caldwell D.G., Davis S., Masey R.J.M., Gray J.O. 2009. Automation in food processing. In: Springer handbook of automation. Springer, Berlin, Heidelberg, Germany, pp. 10411059.

Caldwell D.G. 2012. Robotics and automation in the food industry: current and future technologies. Elsevier, Amsterdam, The Netherlands.

Lamastra L., Trioli G. 2015. Sostenibilità in cantina: la gestione dell'acqua. L'Inf. Agr. 11:2-4.

Matese A., Di Gennaro S.F. 2015. Technology in precision viticulture: a state of the art review. Int. J. Wine Res. 7:69-81.

Nardin G., Gaudio A., Antonel G., Simeoni P. 2006. Impiantistica enologica. Edagricole, Milano, Italy.

Oberti R., Marchi M., Tirelli P., Calcante A., Iriti M., Hočevar M., Ulbrich H. 2013. Selective spraying of grapevine's diseases by a modular agricultural robot. J. Agric. Eng. 44:s2.

ISO. 2006. Environmental management - Life cycle assessment Principles and framework. Norm ISO R- 14040:2006. International Organisation for Standardisation Publ., Geneva, Switzerland.

ISO. 2018. Environmental management - Life cycle assessment requirements and guidelines. Norm ISO R-International Organisation for Standardisation Publ., Geneva, Switzerland.

Italian Patent. 2019. Apparatus and method for automated yeast nutrition during the alcoholic fermentation of grape must.

Rodríguez-Pérez J. 2019. An introduction to human errors. J. Qual. Particip. 41:12-6.

Rojko A. 2017. Industry 4.0 concept: Background and overview. Int. J. Inter. Mob. Tech. 11(5).

Sablayrolles J.M. 2009. Control of alcoholic fermentation in winemaking: current situation and prospect. Food Res. Int. 42:41824.

Sá J., Ferreira L.P., Dieguez T., Sá J.C., Silva F.J.G. 2020. Role of the Industry 4.0 in the Wine Production and Enotourism Sectors. In International Conference on Tourism, Technology and Systems. Springer, Singapore, pp.

Stock T., Seliger G. 2016. Opportunities of sustainable manufacturing in industry 4.0. Procedia Cirp. 40:536-41.

Suzzi G., Tofalo R. 2018. Microbiologia enologica. Edagricole, Milano, Italy.

Trioli G., Sacchi A., Corbo C., Trevisan M. 2015. Environmental impact of vinegrowing and winemaking inputs: a European survey. Internet J. Viticult. Enol. 7(2).

Tugnolo A., Giovenzana V., Beghi R., Guidetti R. 2018. Verso un'enologia 4.0. Parola chiave: connessione. Il Corriere Vinicolo. 91(8).

Vaidya S., Ambad P., Bhosle S. 2018. Industry 4.0-a glimpse. Procedia Manuf. 20:233-8.

Zhang X.-Y., Liu Y.-L., Zhang L., Yuan H.-Y., Kang Y.-L., Sun Z.B. 2007. Influence of meteorological conditions on some quality factors of wine grape. Chinese J. Agrometeorol. 28:326. 